\title{
Resenhas
}

\section{Nascimento da esfera pública no Brasil dos Oitocentos*}

Iara Lis Schiavinatto*

MOREL, Marco. As transformações dos espaços públicos, imprensa, atores politicos e sociabilidades na cidade imperial (1820-1840), Ed. Hucitec, 2005.

A partir de meados da década de 1990, a historiografia luso-brasileira tem visitado o tema "da emergência e ordenação do império luso-brasileiro à definição do império do Brasil" - assunto correlato surge nos estudos históricos hispano-americanos, sobretudo à luz da obra de FrançoisXavier Guerra. Neste prisma, o livro se insere como poucos e areja suas abordagens. Primeiro, por centrar-se nas agitadas décadas de 1820-1840 no Rio de Janeiro. De antemão, busca não projetar a corte para todo o Brasil, como se um fosse gêmeo do outro ou mera decorrência. Antes, considera o Rio de Janeiro uma cidade imperial. Esta acepção, nada ingênua, remete a uma geografia do poder, que se almeja centralizado-e-centralizador em um vasto território, conforme as inspirações literárias e históricas de então do Império Romano. As palavras, as ações e as propostas empreendidas na cidade imperial-simultaneamente, corte da monarquia constitucional - reverberavam com maior contundência na Europa, em especial em Portugal, e no próprio Brasil. Por outro lado, o debate internacional

${ }^{*}$ Resenha recebida em outubro de 2006 e aprovada para publicação em dezembro de 2006.

${ }^{* *}$ Professora do Departamento de História da Unicamp. E-mail: dmm@iar.unicamp.br. 
acerca do liberalismo constitucional, do ideário contra-revolucionário, das memórias e das narrativas sobre as experiências políticas nas Américas e na Europa encontrava aí alargada recepção, divulgação, (re)tradução e (re)apropriação. Neste sentido, o Rio de Janeiro gozava de um forte apelo junto às elites locais e regionais do Brasil, sem que isto, obrigatoriamente, implicasse uma posição unânime e coerente dos atores políticos. Morel logo esclarece: nesse período e nessa cidade, chegou-se, às vezes, a duvidar da pertinência e da necessidade de se lutar e manter a integridade e a unidade do território brasileiro. Em miúdos, não reafirma a idéia de que uma outra parte do Brasil - por suposto, as regiões Norte, Nordeste e Sul - postularia uma quebra ou uma reorganização do território político e uma redefinição da autonomia política de cada uma. Longe disto, tal possibilidade efetiva atravessava a pauta política no Rio de Janeiro. Em circunstâncias tão delicadas e específicas das décadas de 1820-1840, Morel estuda a emergência da modernidade política no Rio de Janeiro. Nessa medida, data o surgimento de tal modernidade e marca as balizas internas dessa periodização.

Seu recorte cronológico desprende-se da primazia das dinâmicas mercantis do império português, ca- racterizadas pela crise do sistema colonial e sua extensão, da desagregação da colônia e também da dificuldade em analisar as singularidades dos governos regenciais. $\mathrm{O}$ autor privilegia certas categorias fundamentais da modernidade política - bem informado pela análise historiográfica e, principalmente, pelas obras de Koselleck e Harbermas, isto é, aborda a experiência histórica na qual a política se torna um campo em si, uma instância do real, que precisa ser estudada, compreendida, racionalizada, normatizada, governada, modificada, se for o caso, e cabe ser exercida por homens hábeis - como postulavam determinadas vertentes na época. Essa modernidade política traz consigo uma série de questõeschave para sua própria estruturação, funcionamento e dinamização. Morel destaca: a elaboração de novos e diversos espaços públicos; o nascimento do homem de letras e seus congêneres - o publicista, o gazeteiro, o redator, a nobreza letrada; as intersecções entre as elites, os homens de letras e os homens que atuam na esfera política-eleitores, elegíveis e eleitos; o novo vocabulário em voga e as disputas pelo domínio da palavra pública; a fundação da noção de opinião pública; a noção de sociabilidade entremeada com a política. A fim de mapear, historicamente, tais categorias 
e não minimizar suas ambigüidades, contradições, justaposições e limites, Morel opta por estudar as trajetórias coletivas das palavras, dos atores politicos e das sociabilidades. O partido da trajetória evita a quimera do progresso, na qual o incremento das associações coletivas e públicas poderia ser um índice do "progresso" diante dos modos de pertencimento coletivo do Antigo Regime. Também se esquiva da percepção linear e "etapista" desse processo de fundação e ordenação do liberalismo constitucional, porque não transcorre de um momento para outro, de forma repentina, por meio de uma brusca ruptura ou fratura. Ao contrário, o autor assinala uma série de fluxos e refluxos culturais, sociais e políticos, idas e vindas, que, ao fim e ao cabo, configuraram a instalação da modernidade política. Convivem, assim, na cidade imperial, os rumores, os pregões, os cartazes, a leitura oral de um manuscrito, ao lado dos textos impressos no formato de periódicos, brochuras, manifestos, catecismos, da cópia autorizada ou não destes textos - manuscritos e impressos - no intuito de reter e transmitir o dito por parte de diferentes sujeitos enunciativos, anônimos, sob pseudônimos, ou não.

A estratégia do autor de colocar vários atores em cena, definidos em virtude da etnia, da posição social, da atuação política e da liderança, enredados às palavras, aos gestos, às redes de solidariedade e de sociabilidade, às disputas por prestígio ou à defesa de seus princípios, vai, aos poucos, demonstrando maneiras pelas quais certos consensos sociais e políticos foram engendrados. Por exemplo, a balança que acabou pendendo a favor das noções de moderação e moderado. Morel demarca também o aparecimento das noções de sociabilidade e opinião pública, enquanto problemas capitais dessa cultura política, porque, nelas, se assenta o entendimento da "verdadeira legitimidade" que asseguraria a vida coletiva. Os próprios atores ocuparam-se desses assuntos devido à sua novidade, à sua grandeza, à sua potência e a seus interesses. É importante destacar que eles não perdem carnadura, não são descaracterizados em nome de um perfil coletivo, apenas evidenciado por números ou generalidades. Atento, Morel entremeia as trajetórias coletivas com perfis biográficos, localiza relações familiares, de negócios, acadêmicas e políticas entre estes diversos homens de letras e, ao mesmo tempo, espia os lugares públicos que fundaram, freqüentaram, elogiaram e até repudiaram.

A esfera pública abarca a noção de Estado, contudo a ele não se restringe ou o encara como a pedra de 
toque da vida coletiva. No intento de distanciar-se do fetiche do Estado enquanto agente da história, motor de seu progresso, Morel trabalha e entrecruza variadas séries documentais de procedências até disparatadas. Não obedece à hierarquia das fontes ou à dignidade do sujeito enunciador. Abre seu texto com o desembarque do livreiro francês Plancher no Rio de Janeiro, na década de 1820. Plancher é figura de proa nessa conjuntura política fluminense, que ecoa pelo Brasil. Todavia, raramente sintetizaram-se sua vida e obra. Tal síntese se estende da formação na França e suas ocupações lá à vinda, forçada, para o Brasil; da tipografia aqui instalada à publicação de periódicos e documentos oficiais sob encomenda do governo pedrino, do catálogo de publicações com obras de autores contemporâneos do pensamento político (Benjamin Constant, para citar um) às memórias sobre a Revolução Francesa, às histórias, aos relatos de viagem e sobre a natureza. Não à toa, Morel abre, assim, o livro. Em uma espécie de feito especular, o leitor faz as vezes de Plancher. Um desembarca no Rio de Janeiro, com poucas chances de voltar, naquele momento, à França. O outro é capturado pela escrita de primeira de Morel. Os dois - Plancher e leitor-em comum descortinam um mundo diferente, mas não completa- mente ignorado. Morel conduz o leitor pelo livro adentro, mantém-no na condição de interlocutor privilegiado todo o tempo, pois precisa explicar as tramas políticas e históricas que constituíram e transformaram os espaços públicos. Sela-se, assim, um pacto de compromisso com o leitor em torno da explicação histórica entremeada à narrativa qualificada, na qual chatice e estultice foram despachadas.

Ao recuperar a trajetória de Plancher, Morel enfatiza as necessidades imediatas de sobrevivência, a vontade de cultivar um público leitor e o rol de autores sobre política de sua preferência. O historiador trabalha no detalhe e vai recompondo um quadro maior. No final do primeiro capítulo, o leitor observa como o impressor intervinha na esfera pública de maneiras distintas, ao tempo em que a moldava. Para situar Plancher, Morel entrecruza uma diversificada série documental que abarca jornais, memórias de diplomatas estrangeiros, listas de livros publicados e para aquisição, chancelas oficiais, autorizações reais, ao lado de uma bibliografia recente e pertinente. Vale-se de diferentes procedimentos histórico-historiográficos: a quantificação das informações, a contraposição de comentários ficcionais e/ou testemunhais sobre o impressor, a documentação sobre ele nos acervos franceses, os concei- 
tos vincados pela cultura política da época, que permeiam sua conduta. Estes procedimentos reaparecem ao longo do livro e conferem densidade histórica à argumentação de Morel.

Sob tais escolhas metodológicas, o autor enfrenta questões candentes da cultura política do período. Entre elas: como ocorrem os processos de produção de identidades políticas dos homens considerados talhados para tal esfera - restauradores, exaltados, moderados - e as metáforas que os nomeiam e qualificam na esfera pública? Como se angaria, rapidamente ou não, prestígio político e social? Quais os critérios de distinção específicos desse momento e seus campos de validade? Quais os gestos, as ações, as palavras que denotam aí as gentes da rua? Cabe assinalar os espaços públicos em pauta e suas rivalidades e adversidades? Por quais razões as formações associativas - clubs, lojas maçônicas, associações filantrópicas, de estrangeiros, sociedades políticas - se erigem em dispositivos importantes da vida coletiva, entre meados da década de 1820 a fins de 1830 , sendo que uma delas, engajada na proposta da Maioridade, impulsionou esse "golpe" e contribuiu deveras para o esvaziamento dessa prática associativa? Quais as fronteiras, os liames e os vínculos entre o espaço público, o espaço doméstico e a rua?
O livro de Morel, com simplicidade na escrita, aliada à fina e segura armação metodológica, coloca o problema da história da esfera pública no Rio de Janeiro, seu vigor e extensão, quando muito já se enfatizou a esfera doméstica, senão a privatização dos interesses no campo do público no Brasil. A partir daí, permite entrever a intensidade das oposições, das contraposições e das justaposições, da ação e reação entre Luzes \& Sombras, que permeiam tais debates políticos e a compreensão de seus atores - sob a clave do monstruoso; da metáfora animal, que propunha o rebaixamento do outro ao reino animal, enquanto o eu enunciativo seria bem qualificado por ser humano; da Perfeição Humana e da Justa Raะão; bem como problematiza, nas conjunturas, os ganhos políticos de uma ou outra ou mais facções dentro das elites e o quanto tais propostas políticas, mesmo as exaltadas e radicais, foram vergadas pela violência da monarquia e pelos adversários na esfera pública. Ele recupera uma modernidade política na qual os processos de exclusão e de produção de desigualdade social e política estavam sendo redimensionados e estavam na ordem do dia. Se o livro se encerra com uma fina ironia sobre a praça que pertence ao povo, seja em Castro Alves, seja em Drummond; por outro lado, não 
desmerece o frescor e o inédito bascu- pelo do livro, latejam vários problemas. lamento desse ideário político, quando Nomearia um: não convém esmiuçar certas promessas democráticas lateja- as formas de gestão da violência, nessa vam nas virtualidades do campo, agora sociedade escravista, na esfera pública autonomizado, da política. No contra- - presumido aí o Estado? 